\title{
Numerical simulation of mechanical properties tests of tungsten mud waste geopolymer
}

\author{
Natalia Paszek, Małgorzata Krystek \\ Silesian University of Technology \\ Civil Engineering Faculty, Department of Structural Engineering \\ e-mail: natalia.paszek@polsl.pl, malgorzata.krystek@polsl.pl
}

\begin{abstract}
Geopolymers are believed to become in the future an environmental friendly alternative for the concrete. The low $\mathrm{CO}_{2}$ emission during the production process and the possibility of ecological management of the industrial wastes are mentioned as main advantages of geopolymers. The main drawback, causing problems with application of geopolymers as a building material is the lack of the theoretical material model. Indicated problem is being solved now by the group of scientists from the Silesian University of Technology. The series of laboratory tests are carried out within the European research project REMINE. The paper introduces the numerical analyses of tungsten mud waste geopolymer samples which have been performed in the Atena software on the basis of the laboratory tests. Numerical models of bended and compressed samples of different shapes are presented in the paper. The results obtained in Atena software were compared with results obtained in Abaqus and Mafem3D software.
\end{abstract}

Key words: geopolymers, material model, Atena software, tungsten mine waste

\section{Introduction}

"Geopolymers are mineral substances obtained synthetically, i.e. by chemical processes that are actually also found in nature, but which there take millions of years." [2] In these words Joseph Davidovits describes geopolymers at the beginning of his book Why the pharaohs built the Pyramids with fake stones [2]. Davidovits is said to be the father of a new branch of chemistry dealing with geopolymers. He is also the author of controversial idea that pyramids in ancient Egypt were made of geopolymer blocks what indicates the first intentional use of geopolymers as a building material. According to Davidovits, Egyptians did not lug massive carved stone blocks, but built pyramids with use of re-agglomerated stone (natural limestone) cast in moulds, treated like concrete [2].

Ancient Egyptians probably discovered possibility of creation of re-agglomerated stones accidentally. Nowadays, it is the commonly known fact, that a secret of fake stones lies in polymeric reaction of pozzolanic material with silicate aquatic solution with addition of a base [3]. Material obtained in that way is called geopolymer and is considered as one of the 
possible building materials to replace cement-based concrete in the future. The most important advantages of geopolymers over the commonly used concrete are low $\mathrm{CO}_{2}$ emission during production process and opportunity of re-usage of industrial by-products such as fly ashes [5].

Scientists indicate different values of the possible reduction of carbon dioxide emission while using geopolymers instead of concrete. For example, according to Provis and van Deventer [6], the emission of $\mathrm{CO}_{2}$ to the environment could be decreased by $30-80 \%$ due to geopolymers. On the contrary, in the paper [7] researchers prove that $\mathrm{CO}_{2}$ emission of geopolymers is only $9 \%$ less than $\mathrm{CO}_{2}$ emission of ordinary Portland cement concrete. These divergences result from different calculation assumptions, considered factors and even the country in which the research was being performed. Nevertheless, the majority of publications shows the benefits of using geopolymers instead of concrete in the aspect of carbon dioxide emission.

As it was mentioned above, some scientists noticed the evidence of using geopolymers in the antiquity. Although it may be difficult to assess if this particular theory is possible, there are many evidences that geopolymers were used in the recent past. Many examples of geopolymer structures already fabricated in different countries, such as Russia, Ukraine, Poland, China, Belgium etc may be found in Provis and van Deventer [6]. Huge structures such as 24-storey buildings, car parks, roads, pavements, drainage collectors, roof tiles and many others are described.

Despite the fact that geopolymers were used in the past, the optimal composition and the optimal method of curing still state a problem which can be solved only by successive laboratory tests. The wide range of possible compositions and curing methods of geopolymers provides the promising opportunity to create many different materials with different characteristics. On the other hand, such variety makes it necessary to perform numerous research works. It is important to notice that there are different types of wastes which can be used in production of geopolymers in different countries. It decreases the cost of transportation of wastes, but simultaneously enforces new researches. The calculations presented in the paper refer to geopolymer based on tungsten mine wastes from tungsten mine Panasqueira in Portugal.

Many studies on geopolymers were carried out worldwide, but researchers are focused mostly on its chemical composition, while the mechanical characteristics of geopolymers have not been recognized yet. Gaining knowledge about mechanical properties of geopolymers, such as the compressive, tensile and flexural strength, Young's modulus or Poisson's ratio, and establishing its material model are the main goals of scientists from Silesian University of Technology within the European research project REMINE (further information can be found at $[8])$.

The paper presents an attempt of adaptation of available numerical material concrete models for modelling geopolymer elements. Numerical calculations were performed on the basis of the outcomes from laboratory tests performed on geopolymer samples at Silesian University of Technology. The elements were recreated in GiD 12.0.7 software and calculations were executed in Atena Studio v5 software. The results were compared with calculations previously performed in Mafem3D software and Abaqus software [4]. 


\section{Laboratory tests}

Similarly to the concrete, geopolymers can differ among themselves in almost every respect. The concept of common geopolymer with unified composition of ingredients does not exist. The paper presents numerical calculations of elements made of geopolymer with particular composition cured in a specified way. Consequently, the outcomes and obtained data are reliable only for elements prepared in the same way. The basis for these studies were laboratory tests performed within the framework of the first step of REMINE project. Mechanical properties tests were carried out on geopolymer samples prepared previously at University of Beira Interior (Portugal) and at Silesian University of Technology (Poland). Samples were made of composition of water-glass, caustic soda, soda silicate and ground waste aggregate from tungsten mine. Composition did not include any coarse aggregate. Samples were cured during first 24 hours in temperature $60^{\circ} \mathrm{C}$ and then in a room temperature $18-20^{\circ} \mathrm{C}[4]$.

Tests were performed on nine samples. Three samples of cylindrical shape $(59 \mathrm{~mm}$ diameter and $120 \mathrm{~mm}$ height) were subjected to the uniaxial compressive strength test. Six remaining samples of rectangular shape $(40 \times 40 \times 145 \mathrm{~mm})$ were used to the flexural strength test. Additionally, the compressive strength test on rectangular samples of dimensions $40 \times 40 \times 40$ $\mathrm{mm}$ was performed. Detailed description of tests and outcomes may be found in conference proceeding [4].

\section{Numerical analyses}

Numerical analyses on the basis of previously mentioned tests were performed in GiD 12.0.7 and Atena Studio v5 software. The main purpose of these analyses was to verify the possibility of adapting the existing material model for cementitious materials available in Atena software to characterize tested geopolymers. In the case of bended samples and compressed rectangular samples, the results obtained in Atena were compared to the results obtained from the analyses previously performed in Mafem3D software and Abaqus software [4].

Samples were defined each time as volumes. The heights and the widths of volumes coincide with the actual dimensions of specimens. The length of elements subjected to bending was equal to $145 \mathrm{~mm}$. These elements were defined as simply supported beams with the support distance of $100 \mathrm{~mm}$ and were loaded with the increasing displacement acting in the center of the beam.

Calculations concerning compressed elements were divided into two steps. The first step included numerical analysis of cubic samples. The length of compressed elements was equal to $72.5 \mathrm{~mm}$. These elements were loaded and supported on, respectively, upper and lower surface with dimensions of 40x40 mm. The second part of analysis of compressed samples referred to cylindrical geopolymer samples. The dimensions of numerical model of cylindrical samples were equal to dimensions of samples tested in laboratory (height: $120 \mathrm{~mm}$ and diameter: $59 \mathrm{~mm}$ ). The load in compressed samples was defined in the same way as in the case of bended samples - as increasing displacement. In both cases, for bended elements as well as for compressed elements, the loads and supports were acting on the elements through steel plates to spread the loads and reactions uniformly. 
The material model called CC3DNonLinCementitious2User was chosen from among material models available in Atena software [1]. The CC3DNonLinCementitious2User material model is defined as Fracture-Plastic Constitutive Model, because it combines plastic behavior under compression loads with tensile (fracturing) behavior. Rankine failure criterion and exponential softening are applied in the fracture model. Furthermore, Menétrey-William failure surface was the basis for defining the hardening/softening plasticity model. The algorithm enables to define and develop these two models separately [1].

The fundamental mechanical properties obtained from tests presented in Górski et al. paper [4] such as Young's modulus and the limit strain were introduced to material model in Atena. The values of the compression strength and the tensile strength were adjusted during the analyses. The analyses were continued until the value of the damaging load in numerical model was equal to the value of damaging load obtained during laboratory tests.

\section{Results and discussion}

\subsection{Uniaxial tensile strength}

The iterative analysis in Atena software allowed to determine the average value of the uniaxial tensile strength of tested geopolymer as equal to $3.40 \mathrm{MPa}$. The results for all samples may be found in Table 1. According to [4] the values obtained from numerical analyses in Mafem3D and Abaqus software amounted to, respectively, $3.78 \mathrm{MPa}$ and 2.82 $\mathrm{MPa}$. The result from calculations in Atena differs by $10 \%$ from the result from Mafem3D and by $21 \%$ from the result from Abaqus software.

Figure 1 illustrates the map of stresses preceding damage of one of the bended samples.

Table 1: The results of numerical simulations in Atena software for all samples

\begin{tabular}{|c|c|c|}
\hline $\begin{array}{c}\text { Number of a } \\
\text { sample }\end{array}$ & $\begin{array}{c}\text { The uniaxial tensile } \\
\text { strength [MPa] }\end{array}$ & $\begin{array}{c}\text { The cubic compressive } \\
\text { strength [MPa] }\end{array}$ \\
\hline \multirow{2}{*}{ G1 } & 3.80 & 28.57 \\
G2 & 2.69 & 24.43 \\
& & 22.06 \\
G3 & 3.87 & 23.61 \\
& & 24.85 \\
G4 & 3.63 & 26.49 \\
& & 25.28 \\
G5 & 3.39 & 25.91 \\
& & 21.38 \\
G6 & 2.99 & 25.65 \\
& \multirow{2}{*}{3.40} & 23.24 \\
& & 25.83 \\
\hline The average & & 24.78 \\
value & &
\end{tabular}




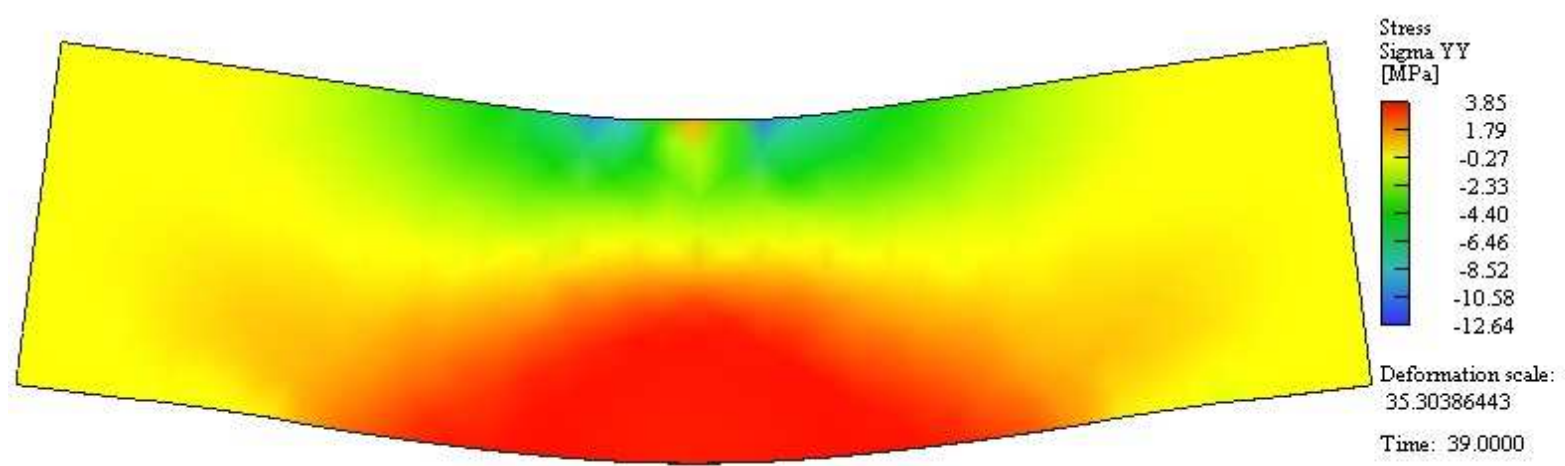

Figure 1: The map of SYY stresses preceding damage of bended sample

\subsection{Cubic compressive strength}

The iterative analysis in Atena software allowed also to determine the average value of the cubic compressive strength of tested geopolymer. The values of the cubic compressive strength for all samples are presented in Table 1. The average value obtained from Atena analyses was equal to $24.78 \mathrm{MPa}$. The values obtained from numerical analyses in Mafem3D and Abaqus software amounted to, respectively, 24.80 MPa and 25.92 $\mathrm{MPa}$ [4]. The result obtained in Atena differs by $4 \%$ from the result from Abaqus software and is approximately the same as the result from Mafem3D.

Figure 2 presents the map of stresses preceding damage of one of the compressed samples.

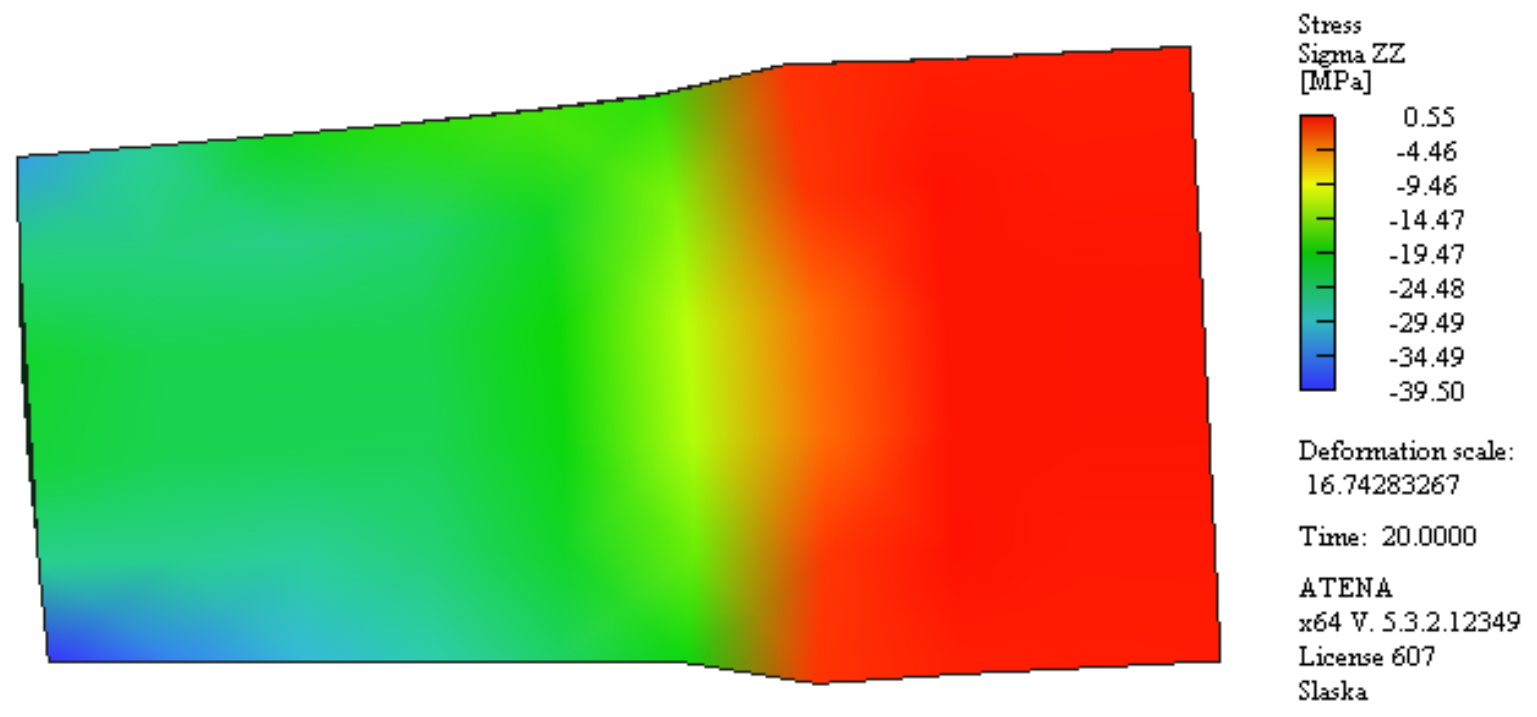

Figure 2: The map of SZZ stresses preceding damage of compressed sample 


\subsection{Cylindrical compressive strength}

The same iterative analysis in Atena software allowed also to determine the average value of the compressive strength of cylindrical geopolymer samples. The values of the compressive strength are presented in Table 2. The average value of cylindrical compressive strength obtained from Atena software was equal to $18.43 \mathrm{MPa}$. The average value of compressive strength obtained during laboratory tests was equal to $16.80 \mathrm{MPa}$ [4].

Table 2: The results of numerical simulations in Atena software for cylindrical samples

\begin{tabular}{|c|c|}
\hline $\begin{array}{c}\text { Number of a } \\
\text { sample }\end{array}$ & $\begin{array}{c}\text { The cylindrical } \\
\text { compressive strength } \\
{[\mathrm{MPa}]}\end{array}$ \\
\hline $\mathrm{G} 1$ & 20.98 \\
$\mathrm{G} 2$ & 16.53 \\
$\mathrm{G} 3$ & 17.78 \\
\hline $\begin{array}{c}\text { The average } \\
\text { value }\end{array}$ & 18.43 \\
\hline
\end{tabular}

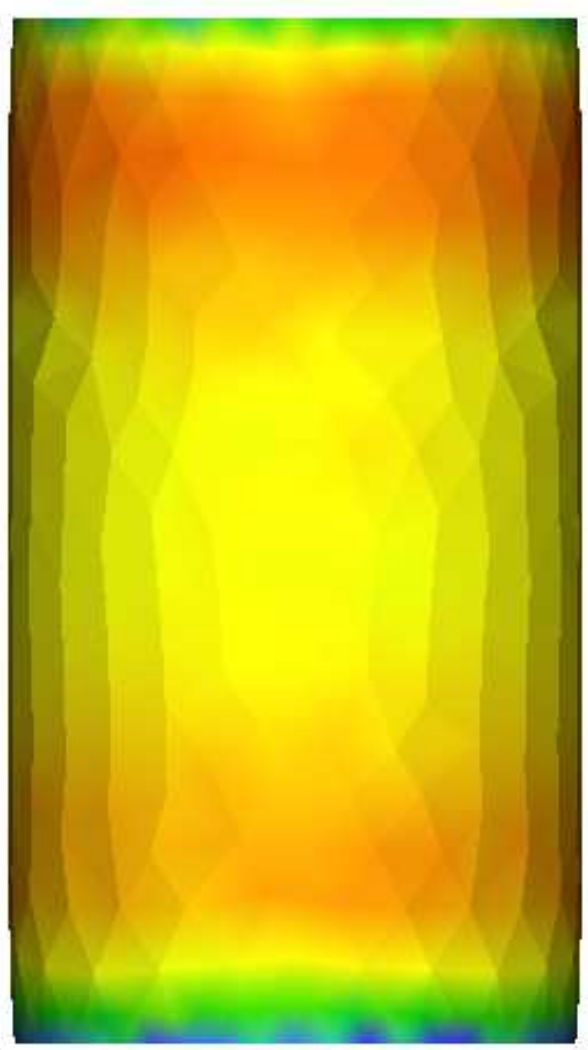

Stress

SizmaZZ

[MPa]

$-\begin{array}{r}-14.74 \\ -\quad-15.53\end{array}$

$-16.31$

$-17.10$

$-17.88$

$-18.66$

$-19.45$

$-20.23$

$-21.02$

Deformation scale:

18.86600921

Time: 20.0000

ATENA

x64 V. 5.3.2.12349

License 607

Slaska

Figure 3: The map of SZZ stresses preceding damage of compressed sample. 


\section{Conclusion}

An attempt of adaptation one of the available numerical material models for cementitious materials for modeling geopolymer structures was made. Numerical analyses on the basis of previously performed tests were executed using GiD 12.0.7 software and Atena Studio v5 software. The results were presented in comparison with previous numerical analyses in Mafem3D and Abaqus software.

The values of the cubic compressive strength were similar in all three cases of numerical simulations. Moreover, numerical analyses performed in Atena and Mafem3D software resulted in obtaining the same value of the cubic compressive strength. Higher divergences were determined during the uniaxial tensile strength investigation. All obtained values seem to be disparate at this point. As in the case of the cubic compressive strength, the most similar were results from Atena and Mafem3D software. The difference between these results was equal to $10 \%$.

Results of numerical analysis of cylindrical samples subjected to the compression in the uniaxial stress state were also presented in the paper. The average value of the compressive strength obtained during calculations in Atena software was equal to $18.43 \mathrm{MPa}$. This value differs by $9 \%$ from the average value of the compressive strength obtained during laboratory tests which was equal to $16.80 \mathrm{MPa}$. Cylindrical geopolymer samples made on the base of the tungsten mud waste have not been calculated with use of another software yet. However, the similarity between results from the laboratory tests and from the Atena indicates, that this software can be suitable for preparing cylindrical numerical models. These results are encouraging, especially taking into account the fact that the numerical model of geopolymer cylindrical samples compressed in the triaxial stress state should be prepared in the future.

The main aim of research works carried out at the Silesian University of Technology is to determine the fundamental mechanical properties of tested geopolymer, develop its material model and finally, propose recommendations for designing geopolymer structures. Research and numerical analyses presented in this paper are only a part of work required to achieve the mentioned objectives. Studies on this new building material are steadily being continued at the Silesian University of Technology. The next stage of research is to investigate the uniaxial tensile strength of geopolymer during laboratory tests. Geopolymer samples are going to be tested also in the triaxial apparatus. The results from these tests will allow to evolve the boundary surface of the geopolymer. The outcomes from this paper indicate that geopolymer material model, which will be developed in the future, may be introduced to Atena software.

\section{Acknowledgements}

The research was performed in the framework of the European research project H2020-MSCA-RISE REMINE.

\section{References}

[1] Červenka V., Jendele L \& Červenka J. ATENA Program Documentation. Part 1. Theory. 2016, http://www.cervenka.cz/products/atena/documentation/ - 14.02.2017. 
[2] Davidovits J. (2009) Why the pharaohs built the Pyramids with fake stones. Saint Quentin, France: Geopolymer Institut.

[3] Davidovits J. (1991). GEOPOLYMERS Inorganic polymeric new materials. Journal of Thermal Analysis. 37, 1633-1656.

[4] Górski M., Krzywoń R., Safuta M., Paszek N., Dawczyński Sz. \& Pizoń J. (2016). Badania cech materiałowych geopolimerów z odpadowych kruszyw pokopalnianych i ich symulacja numeryczne. Materiały Budowlane. 528 (8). 89-91.

[5] Hardjito D. \& Rangan B. V. (2005). Development and properties of low-calcium fly ashbased geopolymer concrete. Perth: Faculty of Engineering Curtin University of Technology.

[6] Provis J., van Deventer J. (2014) Alkali Activated Materials. Melbourne, Australia: Springer.

[7] Turner L. \& Collins F. (2013). Carbon dioxide equivalent $\left(\mathrm{CO}_{2}-\mathrm{e}\right)$ emissions: A comparison between geopolymer and OPC cement concrete. Construction and Building Materials. 43, 125-130

[8] University of Beira Interior. (June 16, 2017). REMINE H2020-MSCA-RISE https://reminemsca.wordpress.com. 